\title{
Relationship between Head Nurses' Self-efficacy and Job Performance
}

\author{
Seham Mohamed Abd Elhamed ${ }^{1,}$ Sahar Mohamed Morsy ${ }^{2}$ \& Amal Sayed Mohamed ${ }^{3}$. \\ 1. Assistant lecturer of Nursing Administration, Faculty of Nursing Assuit University, Egypt. \\ 2. Prof of Nursing Administration, Faculty of Nursing Assiut University, Egypt. \\ 3. Lecturer of Nursing Administration, Faculty of Nursing Assiut University, Egypt.
}

\begin{abstract}
Background: Self-efficacy decides what goals should be chosen to pursue, how these goals can be achieved, and how it reflected upon our job performance._Aim: Assess the relationship between head nurses' self-efficacy and job performance. Study design: Descriptive research design was used. Setting: The study was conducted at Assiut University Main Hospital. Subjects: Consisted of 44 head nurse. Tools: Two tools were used to collect data I): A structured questionnaire sheet which consists of two parts:-Part (1): Personal data sheet which gathered data about: gender, age, years of experience, educational qualification, and marital status. Part (2): Self efficacy assessment scale which includes 50 statements. II): Job performance checklist sheet which includes 3 main categories (general characteristics, soft skills, and nursing care). Results: The majority of head nurses had low self-efficacy and more than half of them had inadequate job performance $(82 \%$ \& 59\%) respectively. Conclusion: There were statistical significant difference between head nurses' self-efficacy and job performance. Recommendations: Head nurses' self-efficacy training program should be done.
\end{abstract}

Keywords: Self efficacy, Head nurses \& job performance.

\section{Introduction}

The most important valuable parts of any organization are its human resources. Nurses, are the most significant and largest human resource of healthcare organization, so, a nurse plays a very important role in improving the social health of patients and clients. No healthcare organizations can accomplish any success without having qualified nurses with high self-efficacy (Papastavrou et al., 2011).

Head nurse or first line manager have very important role in achieving organizational objectives, presence of head nurses as a member from health care team which is a part of health care system now become very important, head nurse spends the whole working hours in performing different administrative functions as well as participating in direct and indirect patient care activities (Cziraki, 2012). Head nurses are usually in close contact with other staff nurses so, the effectiveness of their activities and management skills they have could be beneficial for their health care organizations (Van Oostveen, 2015).

Verghese, (2016) explained three management skills that must be presented or acquired by all head nurses and described them as follows; 1) Technical skills, which means "how to skill", the knowledge and competency in activities involves; methods, procedures, and process. Also it is a combination of formal education, training and job experience, 2) Human skills are the interpersonal skills which allow head nurses to work with people and assist them to communicate, lead and motivate subordinates, also help head nurses to nurture team spirit, and 3) Design skills refer to the ability to solve problems in ways that will benefit the organization. All the previous talents and skills require head nurses to have high level of self-efficacy which is discussed in the last decades by Bandura's.

Bandura's (1978 and 2014) summarized social cognitive theory which includes self-efficacy beliefs, outcome expectations, and behavioral goals, and emphasizes the role of self-beliefs so individuals are viewed as self -organizing, proactive, self-reflecting, and self-regulating rather than reactive organisms shaped by environmental forces or driven by concealed inner impulses. Other behaviorists were not taking into consideration the inner workings of a cognitive approach to motivation and lack of situational awareness in psycho analysis. So Bandura blended the environment, behavior, and cognitive responses together into social cognitive theory.

Self-efficacy was defined by Pajares, (2007) as a person's belief about his / her abilities to perform particular behaviors which lead to a certain results. Lauder et al., (2008) added that self-efficacy affects one's motivation, learning skill, and professional progress. Meanwhile Stump et al., (2012) indicates that self- efficacy not only affects nurses' caring abilities, but also prevents many clinical errors in clinical practice. Washington \& Moxley, (2013) added that self-efficacy is a personal, situational, and context-dependent issue. Professional self-efficacy 
deals with particular behaviors and performing the different skills necessary to become professional nurse. Head nurse with high self-efficacy will be more confident in their work and will make amazing accomplishment (Wang, 2016).

Successful head nurses must exert much effort, accept authority, responsibility and assume accountability in implementing the executive and managerial functions which includes (planning, organizing, delegating, leading and controlling). Head nurses are also responsible for the implementation of health care programs and standards of patient care at her/his unit/ward. They supervise and evaluate the quality of patient care provided by their staff, motivate the nursing staff to provide the quality of nursing care, promote and utilize the quality standards (Jose, 2012).

Self-efficacy is expected to be one of the factors that affecting nurses' job performance. High self-efficacy improves the quality of care provided by nurses and in the end improves individual and organizational job performance (Zengin et al., 2014).

The job performance of head nurse is very important because of their strong effect on staff nurses. They interact with most staff nurses on an everyday basis and must act as a good role models, if they role weakly or were unsuccessful to stimulate their nursing staff, it may affect dramatically the work job performance of staff nurses which will lead to the desire to leave the unit or to work with less quality, low productivity, dissatisfaction and other passive attitude toward work and organization like to decrease the level of commitment to their work. So head nurses must continuously evaluate staff job performance (Luu, 2012).

\section{Significance of the study}

Nowadays many studies were published in professional articles and journals nationally and internationally which focused in developing and improving students' self-efficacy but for nurses already employed are not taking the same interest such as Pavani \& Agrawal, (2015) study of selfefficacy and academic achievement among college students, Mohammed \& Shahabuddin, (2016) addressed self-efficacy, motivation and their relationship to academic performance of Bangladesh College Students, Kaviyabala \& Sayujya, (2017) determined self-efficacy among nursing students, Zaki, (2017) addressed effects of different evaluative feedback on students' self-efficacy in learning. This was the motive for the researcher to assess relationship between head nurses' selfefficacy and job performance at Assiut University Main Hospital.
The present study aimed to

Assess the relationship between head nurses' selfefficacy and job performance at Assiut University Main Hospital.

\section{Research Questions}

Q1: What are the head nurses' self-efficacy level?

Q2: What are the head nurses' job performance?

Q3: Is there relationship between head nurses selfefficacy and job performance?

\section{Subject \& methods}

1. Technical design: This design involves the research design, subject, and data collection tools.

Research design; descriptive research design was used in the present study.

Study subject; convenient sample was used ( $n=44$ head nurses.

Data collection tools: two tools were used to collect data of the present study.

Tool I: A structured questionnaire sheet which consists of two parts: - Part (1): personal data sheet which gathered data about: gender, age, years of experience, educational qualification, and marital status. Part (2): Self - efficacy assessment scale; which was developed by El-Adel, (2001) which include 50 statements. Participants will be asked to give a response for every question using 4 point rating scale which ranged from (1) for rarely, (2) for sometimes, (3) for often and (4) for always.

\section{Scoring System.}

All participant response will be totaled and it is ranged from 50 to 200 which are divided into three levels: if the participant obtains 50-99 it means low level of self-efficacy, from100-149 it means moderate level of self-efficacy and from 150-200 it means high level of self-efficacy (Saleh, 2012).

Tool (II): Job performance observational checklist sheet is developed by Youssif, (2017) and modified by researcher based on the current and relevant literature (Ali, (2016), Abdul Fattah, (2014), Kelly \&Tazbir, (2013), Luu, (2012), Mohamed, et al., (2007). It consists of 3 categories includes the following; 1) General characteristics; which includes three dimensions; attendance and punctuality (3 items), appearance (4 items), and work habits (8 items). 2) Soft skills; which includes five dimensions; communication with staff (6 items), communication with patients ( 7 items), innovation (2 items), documentation (7 items), and keeping up to date technically (5 items). 3) Nursing care; which includes two dimensions; Nursing care plan activities (9 items), and preventive measures and patient safety (6 items). Each item will be observed and audited by the researcher and the rating ranged from (1) for no and (2) for yes. 


\section{Scoring system}

If the participants obtained $\geq 70 \%$ it means participants had adequate job performance, if the participants obtained $<70 \%$ it means the job performance was inadequate (Oladokun, \& Adebanjo, 2008).

\section{2- Administrative design:}

Official letter from the Dean of Nursing Faculty Assiut University directed to Directors of Assiut University Main Hospital (Medical and Nursing), and all departmental Heads in order to collect the necessary data for the present study.

3- Operational design: Preparatory phase; it includes reviewing the available literature concerning the study topics and Arabic translation of the study tools was done. It took about three months from October to the end December 2017.

\section{Ethical considerations}

Research proposal was approved from Ethical Committee at Nursing Faculty, Assiut University. The study followed common ethical principles in clinical research, then oral agreements were taken from all participants who participated in the present study, after informing them that they have the right to refuse/ participate/ withdraw from the study without any rational at any time, confidentiality and anonymity were assured, during collection of data participants were told that all obtained data were used only for purpose of research.

\section{Validity}

Face validity was done to assure accurate comprehension of study tools. It was done through jury by (expert opinions) which was composed of 3 professors and 2 assistant professors from Nursing Administration Department and Community Health Nursing Department, Faculty of Nursing, Assiut University. Also content validity was checked and analyzed using confirmatory factor analysis test to assure (importance, clearness, and accountability) and its result was $\geq \mathbf{1 . 8}$ for all items of the study tools, so all items were confirmed.

\section{Pilot study}

Pilot study was done to estimate time needed to fill the questionnaire form. The questionnaire took from 20-30 minute also to detect any problems that may encounter during data collection phase. It was applied on five Head nurses (10\%) from Assiut University Main Hospital. Data collected from the pilot study were analyzed using Cronbach's Alpha Co- efficient test; $\alpha=0.86$ for each item of self-efficacy scale. The head nurses included in the pilot study were excluded from the total study sample.

\section{Filed work}

After ensuring the clarity and understandability of the study tools the actual data collection was started in January 2018 by the researcher through distributing questionnaire form for head nurses. The researcher construct meeting with every head nurses in her/his departments at Assiut University Main Hospital and explained the purpose of the study. Then they filled the questionnaire form. The whole duration to collect data of the self-efficacy questionnaire form was about one month. The investigator observed the head nurses job performance three times consecutive to assure this task was done or not. This phase took about five months from January to May2018.

4-Statistical design:

Data entry and statistically analysis were done using Statistical Soft Ware Package for social science (SPSS ver.16.0). Data were presented using descriptive statistics in the form of frequencies, percentages, multiple regression and correlation matrix. Statistical significance was considered at Pvalue $\leq 0.05$. 


\section{Results}

Table (1): Head Nurses Personal Data at Assiut University Main Hospital (n= 44).

\begin{tabular}{|c|c|c|c|}
\hline \multicolumn{2}{|r|}{ Personal Data } & No. & $\%$ \\
\hline \multirow[t]{4}{*}{ Age: (years) } & $25-<35$ & 7 & 15.9 \\
\hline & $35-<45$ & 29 & 65.9 \\
\hline & $45 \geq 55$ & 8 & 18.2 \\
\hline & Range: $25-52$ years. & \multicolumn{2}{|c|}{ Mean \pm SD $(38.84 \pm 5.95)$} \\
\hline \multirow[t]{2}{*}{ Gender } & Male. & 4 & 9.1 \\
\hline & Female. & 40 & 90.9 \\
\hline \multirow{3}{*}{$\begin{array}{l}\text { Educational } \\
\text { Levels: }\end{array}$} & Secondary technical nursing school diploma. & 5 & 11.4 \\
\hline & Bachelor degree in nursing science. & 35 & 79.5 \\
\hline & Master degree in nursing. & 4 & 9.1 \\
\hline \multirow[t]{2}{*}{ Marital status } & Single. & 5 & 11.4 \\
\hline & Ever Married. & 39 & 88.6 \\
\hline \multirow[t]{3}{*}{ Years of ex. } & $<15$ years & 13 & 29.5 \\
\hline & $\geq 15$ years & 31 & 70.5 \\
\hline & Range: $2-35$ years. & \multicolumn{2}{|c|}{ Mean \pm SD $(17.2 \pm 6.26)$} \\
\hline
\end{tabular}

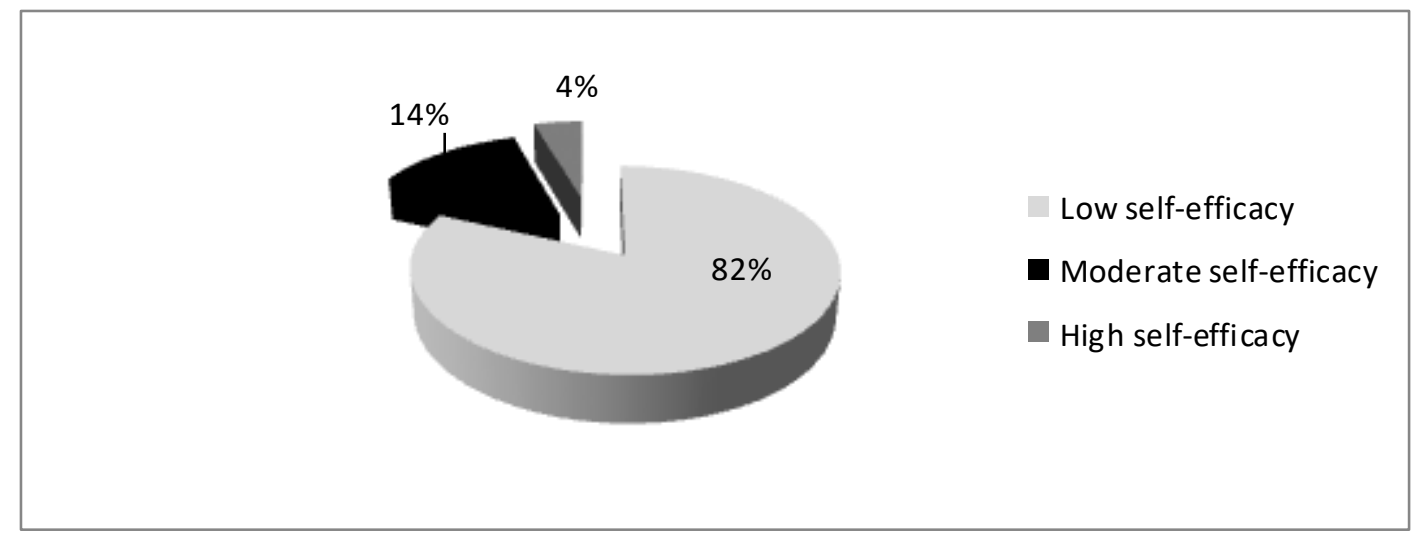

Figure (1): Head Nurses' Self-efficacy levels at Assiut University Main Hospital (no. $=44$ ).

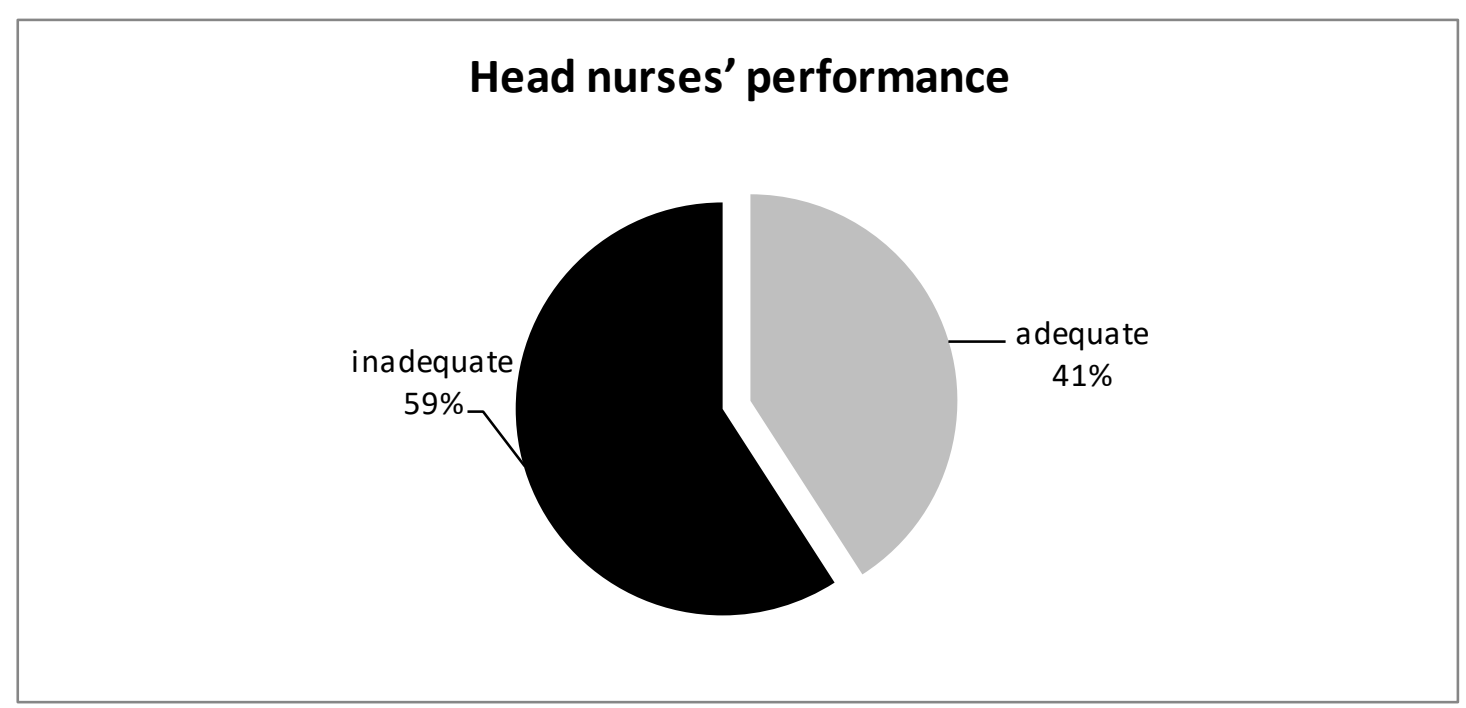

Figure (2):- Head Nurses' Job performance adequacy at Assiut University Main Hospital (no. = 44). 
Table (2): Head nurses' Job Performance Dimensions at Assiut University Main Hospital ( $n=44)$.

\begin{tabular}{|c|l|c|}
\hline \multicolumn{2}{|c|}{ Job Performance Dimensions } & Mean \pm SD \\
\hline \multirow{4}{*}{ General Characteristics } & Attendance and Punctuality & $5.39 \pm 1.15$ \\
\cline { 2 - 3 } & Appearance & $7.25 \pm 1.42$ \\
\cline { 2 - 3 } & Work Habits & $13.98 \pm 2.68$ \\
\cline { 2 - 3 } & Total & $26.61 \pm 4.93$ \\
\hline \multirow{4}{*}{ Soft skills } & Communication è staff & $6.27 \pm 1.45$ \\
\cline { 2 - 3 } & Communication è patients & $7.84 \pm 1.27$ \\
\cline { 2 - 3 } & Innovation & $1.1 \pm 0.44$ \\
\cline { 2 - 3 } & Documentation & $6.89 \pm 1.47$ \\
\cline { 2 - 3 } & Up to date technically & $6.61 \pm 1.49$ \\
\cline { 2 - 3 } & Total & $\mathbf{2 8 . 7 \pm 3 . 1}$ \\
\hline \multirow{3}{*}{ Nursing care } & Nursing care plan activities & $12.55 \pm 3.08$ \\
\cline { 2 - 3 } & Preventive and patient safety & $10.07 \pm 1.78$ \\
\cline { 2 - 3 } & Total & $22.61 \pm 4.41$ \\
\hline & \multicolumn{1}{|c|}{ Total performance } & $77.9 \pm 11.5$ \\
\hline
\end{tabular}

Table (3): Multiple regression analysis between Head Nurses' self-efficacy and Personal data at Assiut University Main Hospital (no. = 44).

\begin{tabular}{|l|c|c|c|}
\hline \multicolumn{1}{|c|}{ Items } & Beta & t & P. value \\
\hline Age & 0.158 & 0.65 & 0.518 \\
\hline Gender & $-0.042-$ & $-0.222-$ & 0.825 \\
\hline Educational level & $-0.139-$ & $-0.678-$ & 0.502 \\
\hline Marital status & $-0.326-$ & $-2.010-$ & 0.552 \\
\hline Years of experience & $-0.160-$ & $-0.584-$ & 0.563 \\
\hline
\end{tabular}

Dependent variable (Self efficacy)

Table (4): Multiple regression analysis between Head Nurses' Job Performance and Personal data at Assiut University Main Hospital (no. = 44).

\begin{tabular}{|l|c|c|c|}
\hline \multicolumn{1}{|c|}{ Items } & Beta & t & P. value \\
\hline \hline Age & $-0.287-$ & $-1.131-$ & 0.265 \\
\hline Gender & 0.041 & 0.207 & 0.837 \\
\hline Educational level & 0.042 & 0.194 & 0.847 \\
\hline Marital status & $-0.043-$ & $-0.254-$ & 0.801 \\
\hline Years of experience & 0.307 & 1.064 & 0.294 \\
\hline
\end{tabular}

Dependent variable (Job performance)

Table (5): Correlation between Head Nurses' Self-efficacy and Job Performance Dimensions at Assiut University Main Hospital (no. = 44).

\begin{tabular}{|l|l|c|}
\hline \multicolumn{1}{|c|}{ Job performance } & & Self-efficacy \\
\hline \hline \multirow{2}{*}{$\begin{array}{l}\text { General } \\
\text { Characteristics }\end{array}$} & Pearson correlation coefficient $(\mathrm{r})$ & 0.21 \\
\cline { 2 - 3 } & P. value & 0.11 \\
\hline \multirow{2}{*}{ Soft skills } & r & 0.65 \\
\cline { 2 - 3 } & P. value & $0.000^{* *}$ \\
\hline \multirow{2}{*}{ Nursing care } & r & 0.19 \\
\cline { 2 - 3 } & P. value & 0.32 \\
\hline Total performance & r & 0.46 \\
\cline { 2 - 3 } & P. value & $0.05^{*}$ \\
\hline
\end{tabular}

* Significant at the 0.05 level (2-tailed).

**Significant at the 0.01 level (2-tailed). 
Table (1): Shows that the majority of head nurses were female, ever married, having bachelor degree in nursing science and having 15 years' experience and more $(90.9 \%, 88.6 \%, 79.5 \%$, and $70.5 \%$ ) respectively, and nearly two thirds of them aged $35 y e a r s$ to less than 45 years old ( $65.9 \%$ ).

Figure (1): Shows that the majority of head nurses had low self-efficacy (82\%).

Figure (2): Shows that more than half of head nurses had inadequate job performance (59\%).

Table (2): Shows that head nurses achieve the

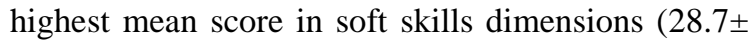
$3.1)$.

Table (3): Reveals the order of personal data which has impact on head nurses' self-efficacy as followed marital status, years of experience, age, educational level, gender with no statistical significant difference.

Table (4): Reveals the order of personal data which has impact on head nurses' job performance as followed years of experience, age, marital status, educational level, gender with no statistical significant difference.

Table (5): Revealed that there is positive moderate correlation between head nurses' self-efficacy and total job performance with statistical significant difference $(\mathrm{P} \leq 0.05)$.

\section{Discussion}

High levels of self-efficacy increase the sense of self-control and job performances and help one to perform tasks with higher efficiency level (Lauder, et al., 2008). Moreover, Kuiper, et al., (2010) added that self-efficacy makes a difference in personnel thoughts, feelings, and actions. The individuals with high levels of self-efficacy are selected to perform more challenging tasks, start and continue activities, attain a positive outcome and set higher goals for themselves, eventually increasing their commitment to these goals. Self-efficacy creates motivation as well as improving job performance.

From the findings of the current study, the majority of head nurses had low self-efficacy. These findings were disagreement with study done by Nagy \& Mohammed, (2018) as they found that the highest percentage of the first line nurse manager were high level of self-efficacy meanwhile, the lowest percentage had low level of self-efficacy.

From the findings of the current study, more than half of head nurses had inadequate job performance. This might be due to lack of training and guidance regarding developing and improving head nurses selfefficacy, autonomy, and self-management leads to lowering head nurses' performance. In addition to nursing directors at Assiut University Main Hospital not providing opportunities to head nurses to discuss causes of performance inadequacy in an attempt to enhance and improve job performance because the highest percentage of nursing directors at Assiut University Main Hospital tend to be more autocratic in their decision making styles that don't allow discussion with subordinates (Sayed, 2012).

These results go in the same line with the study done by Helaly, (2013) who found that about half of head nurses had inadequate job performance. But these findings were inconsistent with the study done by ElSayed, (2010) who found that the majority of head nurses working at Mansoura Urology and Nephrology Center had adequate job performance.

From the findings of the current study, head nurses achieve the highest mean score in soft skills. This might be due to self-efficacy improve attitude and soft skills of head nurses include communication, innovation, keeping up to date technically. This result go in the same line with study done by Pereira \& Duarte, (2012) who found that when soft skills developed and enhanced, self-efficacy was promoted, and it is fundamental to competent performance, and these findings were consistent with the study done by Ismail, (2019) who stated that soft skills achieve highest mean score for nursing students.

From the findings of the current study, there were no statistical significant difference between personal data and self-efficacy. These results incongruent with the study done by Zhang et al., (2017) as they found that there was a statistically significant difference between self-efficacy and marital status. Moreover, these results inconsistent with study done by Lan $\boldsymbol{\&}$ Qun, (2018) as they found that the self-efficacy of the married person was higher than that of the single person, because perceive more family support, thus promoting the improvement of self-efficacy.

Findings of the current study, shows that there were no statistical significant difference between personal data and job performance. These results disagreed with study done by Helaly, (2013) who found that there was a positive correlation among gender, educational level, and years of experience with job performance of head nurses without statistical significant difference. Also from the researcher point of view this might be due to age, gender, educational level, marital status, and years of experience, all of them are not affecting the level of self-efficacy or job performance, it means that studied head nurses are in need to be trained to improve their self-efficacy as there's a homogeneity among studied head nurses. The majority of them have low self-efficacy even the minority which have high self-efficacy by chance, family support and other variables. 
From the findings of the current study, there is positive moderate correlation between head nurses' self-efficacy and job performance with statistical significant difference. These findings are consistent with the study done by Lauder, et al., (2008) who found that self-efficacy has an impact on job performance through mediating the connection between previous exposures and actions. In addition, these findings are agreed with the study done by Elmosdy, (2014) who found that there were statistical significant effects of self-efficacy and job performance achievement.

Moreover, this results findings agreed with the study done by Hughes et al., (2017) as they found that there were a statistical significant relation between perceived self-efficacy and successful job performance, and these results findings consistent with study done by Nikolaou \& Tsaousis, (2018) as they found significant relationship was found between self-efficacy and job performance of head nurses.

\section{Conclusions}

In the light of the present study findings, the following conclusions can be drawn as:

It was concluded that the majority of head nurses had low self-efficacy and more than half of them had inadequate job performance, and there were no statistical significant difference between personal data and head nurses self-efficacy and job performance. Also, there is positive moderate correlation between head nurses' self-efficacy and job performance with statistical significant difference.

\section{Recommendations}

In the light of the study results, the following recommendations will be suggested

- Head nurses' self-efficacy training program should be done.

- Regular meeting should be done with medical and nursing directors to discuss causes of head nurses' performance inadequacy.

- Training program to improve head nurses' job performance should be done.

- Further research studies are needed to assess the effect of self-efficacy training program on enhancing job performance.

\section{References}

1. Abdul Fattah, H., (2014): Evaluation of Head Nurses Administrative Tasks Performance at Units of Teaching and Non-Teaching Hospitals in Kirkuk City: Comparative study. 5(7): 55, 83.
2. Ali, H., (2016): Assessment of the Head Nurses' Performance Regarding Staff Management at the Units of Al-Najaf ALAshraf City Hospitals. Kufa journal for nursing sciences, 6 (3):120-122.

3. Bandura, A., (1978): Self-efficacy mechanism in human agency. American psychologist, 37(2): 122 .

4. Bandura, A., (2014): Regulation of Cognitive Processes Through Perceived Self - Efficacy. Developmental Psychology, 25 (5): 729-735.

5. Cziraki, K., (2012): Factors that attract and retain registered nurses in the first-line nurse manager role. McMaster University, pp.6.

6. El -Mosdy, M., (2014): Psychometric properties of the self-efficacy for clinical evaluation scale in Turkish nursing students. J Clin Nurs, 23 (8): 976-984.

7. El-Adel, A., (2001): Self-efficacy Scale. The Anglo. Egyptian bookshop, Cairo.

8. El-Sayed, T., (2010): Study the Magnetism Dimensions for Satisfaction of Nursing Staff and Patient in Urology and Nephrology Center at Mansoura University. Unpublished Master Thesis, Tanta University, Pp. 95.

9. Helaly, S., (2013) : Emotional Intelligence and its Relation to Nursing Job performance among Nurses at Mansoura University Hospital and Urology and Nephrology Center .Med. J. Cairo Univ.,81(1):689-697.

www.medicaljournalofcairouniversity.net

10. Hughes, A., Galbraith, D., \& White, D., (2017): Perceived Competence: A Common Core for Self-Efficacy and Self-Concept? Journal of Personality Assessment, 93(3): 278289. doi:10.1080/00223891.2017.559390.

11. Ismail, N., (2019): Analysis of Soft Skills on Self-Efficacy in Matriculation College Students through Hermeneutic Method. JoMOR, 1(23) 30 .

12. Jose, G., (2012): Head Nurse. Available at: www. Scribed. Com/ doc/ 24035361/ Head Nursing. Tool.

13. Kaviyabala, D., \& Sayujya, C., (2017): selfefficacy among nursing students. International Journal of Current Research. 9(8):55748-55751.

14. Kelly, P., \&Tazbir, J., (2013): essentials of nursing leadership and management. Third edition, Amazon.com, Pp. 15.

15. Kuiper, R., Murdock N., \& Grant, N., (2010): Thinking strategies of baccalaureate nursing students prompted by self-regulated learning strategies. J Nurs Educ. 49(33): 429-436. 
16. Lan, W., \& Qun, W., (2018): Clinical nurses self-efficacy and influencing factors [J]. Nursing Research, 22(12): 3303-3305.

17. Lauder, W., Watson, R., Topping, K., Holland, K., Johnson, M., \& Porter, M., (2008): An evaluation of fitness for practice curricula: self-efficacy, support and selfreported competence in preregistration student nurses and midwives. J Clin Nurs. 17(18): 1858-1867.

18. Luu, T., (2012): Training Management Skills for First-line Managers: case: company X. Mikkeli University of applied sciences, Pp.11.

19. Mohamed, G., Mohamed, N., \& Gabr, H., (2007): Job description for Head Nurses in Surgical Units at Mansoura University Hospital. ASNJ. 6(2): 39-50.

20. Mohammed S., \& Shahabuddin, A., (2016): Self-Efficacy, Motivation and Their Relationship to Academic Performance of Bangladesh College Students, College Quarterly.10 (1): 1-9. Available: http://www.senecacollege.ca/quarterly/2007vol10-num01 winter/chowdhury_shahabuddin.html.

21. Nagy, F., \& Mohammed, R., (2018): An Investigation of the Relationship between Transformational Leadership and Self Efficacy of the First Line Managers of Minia University Hospital. IOSR Journal of Nursing and Health Science (IOSR-JNHS) e-ISSN: 2320-1959.pISSN: 2320-1940. 7(1):83-94. www.iosrjournals.org

22. Nassar, R., (2011): Effects of models of organizing patient care on productivity at Shebin El Kom Hospitals. Faculty of Nursing Menoufyia University. M.Sc. Pp.76.

23. Nikolaou, I., \& Tsaousis, I., (2018): Selfefficacy in the Workplace; exploring its Effects on Occupational Stress and Organizational Commitment. International Journal of Organizational Analysis, 10(4): 327-342.

24. Oladokun, V., \& Adebanjo, O., (2008): Predicting students academic performance using artificial neural network: A case study of an engineering course.

25. Pajares, F., (2007): Self-efficacy beliefs in academic settings. Review of educational research, 66(4): 543-578.

26. Papastavrou, E., Efstathiou, G., \& Charalambous, A., (2011): Nurses' and patients' perceptions of caring behaviours: quantitative systematic review of comparative studies. J. Adv. Nurs. 67(6): 191-205.
27. Pavani, S., \& Agrawal, G., (2015): A Study of Self-Efficacy and Academic Achievement among College Students. Online Journal of Multidisciplinary Research. 3(1): 28-32. Available at: http://files.eric.ed.gov/fulltext/EJ773185.pdf.

28. Pereira, A., \& Duarte, O., (2012): Engineering undergraduates' perceptions of soft skills: relations with self-efficacy and learning styles. Procedia - Social and Behavioral Sciences. 55(44):843 - 851. International conference on new horizons in educationist.

29. Saleh, S., (2012): Future anxiety and its relation with self-efficacy and aspiration level among faculty of nursing students, unpublished Doctorate degree Thesis, Faculty of Nursing, Elminia university, Pp.60.

30. Sayed, A., (2012): Nurses managers' decision making and its effect on staff nurses' satisfaction and job performance, unpublished Doctorate degree Thesis, Faculty of Nursing, Assuit University, Pp.65.

31. Stump, G., Husman, J., \& Brem, S., (2012): The Nursing Student Self-Efficacy Scale: development using item response theory. Nurs Res. 61(3): 149-158 .doi: 10.1097/NNR.0b013e318253a750).

32. Van Oostveen, C., (2015): Nurse staffing issues are just the tip of the iceberg: a qualitative study about nurses' perceptions of nurse staffing, Int J Nurs Stud, 52(33):13001301.

33. Verghese, C., (2016): The nurse administrator. New Age International (P) Ltd., Publishers. $1^{\text {st }}$ Ed., chapter 4,Pp. 76.

34. Wang, C., (2016): Relationship between social support and self-efficacy in women psychiatrists, Institute of Nursing, Binzhou Medical University, Yantai, Shandong.

35. Washington, O., \& Moxley, D., (2013): Selfefficacy as a unifying construct in nursing-social work collaboration with vulnerable populations. Nurs Inq. 20(1): 42-50. doi: 10.1111/nin.12012.

36. Youssif, A., (2017): Staff Performance Appraisal System and its Relation to Their Job satisfaction and Empowerment: Developing Performance Appraisal Tool. IOSR Journal of Nursing and Health Science. 6(2): 25-26. ISSN: 2320-1959. Available at: www.iosrjournals.org.

37. Zaki, R., (2017): Effects of different evaluative feedback on students' self-efficacy in learning. Journal of Education and Practice www.iiste.org ISSN 2222-1735 (Paper) ISSN 2222-288X. 7(20):55-56. 
38. Zengin, N., Pinar, R., Akinci, A., \& Yildiz, H., (2014): Psychometric properties of the selfefficacy for clinical evaluation scale in Turkish nursing students. J Clin Nurs. 23(8): 976-984. doi: 10.1111/jocn.12257.

39. Zhang, X., Jun, X., Chai, S., Lei, M., \& Lopez, V., (2017): Advances in Social Science, Education and Humanities Research, volume 172. $4^{\text {th }}$ International Conference on Education, Management, Arts, Economics and Social Science. 